\title{
A impossibilidade do amor na poesia de Fernando Pessoa à luz da filosofia de Ortega y Gasset
}

\author{
Carina Marques Duarte* \\ Cristina Catâneo da Silva**
}

\begin{abstract}
Resumo: Na obra de Fernando Pessoa o amor surge como a grande impossibilidade. Tal impossibilidade está relacionada com sua falta de compenetração com a realidade, com o fato de o poeta não conseguir apreender sua circunstância. Não apreendendo a circunstância, Pessoa não se constitui enquanto indivíduo. Logo, não consegue responder ao outro. O estado amoroso é caracterizado pelo empobrecimento da atenção, pelo abandono de si para ir em direção ao outro e pela busca da perfeição do amado. Além disso, o individuo que ama sente a necessidade de dissolver a sua individualidade na individualidade do amado e de absorver a individualidade do amado na sua. Foi isto que Fernando Pessoa não conseguiu fazer ou, talvez, do que abdicou em favor da sua obra.
\end{abstract}

\begin{abstract}
In Fernando Pessoa's work, love appears as a great impossibility. This impossibility is related to his incapacity to understand reality and apprehend his circumstances. By not apprehending the circumstances, Pessoa did not unify himself as an individual and therefore could not respond to the other. The state of love is characterized by the impoverishment of attention, by the neglect of oneself to move towards the other, and by the search for the perfection of the beloved. Moreover, an individual who loves feels the necessity of dissolving his/her individuality in the individuality of the beloved and of absorbing the individuality of the beloved in his/her own. This is what Fernando Pessoa could not do or (perhaps) what he abdicated on behalf of his work.
\end{abstract}

\section{Considerações Iniciais}

Fernando Pessoa é um desses autores cuja obra, por mais que seja lida e submetida a estudos teóricos, sempre apresenta pontos de interrogação e possibilidade de novas leituras. A galeria de personagens dramáticas criada pelo poeta português, associada à profundidade dos seus textos líricos, fascina e inquieta a leitores e críticos.

Desse modo, aqueles que se propõem a efetuar uma análise da obra pessoana já de início se deparam com uma angústia: o pressentimento de que não se conseguirá dar conta da

\footnotetext{
* Carina Marques Duarte é professora, graduada em Letras pela UFRGS no ano de 2007. Desde 2006, atua como pesquisadora no Círculo de Pesquisas Literárias.

Cristina Catâneo da Silva é professora, graduada em Letras pela UFRGS no ano de 2007.
} 
grandiosidade da mesma. Apesar de priorizarmos, neste artigo, o amor, ou melhor, sua impossibilidade em Pessoa, é com a referida angústia que empreendemos tal tarefa.

A questão do amor se apresentou diante dos nossos olhos como um enigma. Afinal, Fernando Pessoa amou ou não amou? Qual era o significado deste sentimento para o poeta? Como o amor refletiu em sua poesia? E, partindo do princípio de que o amor não tenha se concretizado em sua vida, o que o impediu de amar? Estes foram alguns dos questionamentos que impulsionaram este trabalho e aos quais buscamos responder utilizando como pressupostos teóricos os Estudos Sobre o Amor do filósofo espanhol Ortega y Gasset.

\section{Ortega y Gasset e sua contemporaneidade com Fernando Pessoa}

Ortega y Gasset, filósofo espanhol da primeira metade do século XX, nasceu em 1883 e começou a sua vida intelectual numa Espanha que vivia um momento de estagnação social e de desordem política, econômica e cultural. Ortega y Gasset viveu o chamado 'desastre nacional' que foi a derrota sofrida pelo seu país na guerra que moveu contra os Estados Unidos e que resultou na perda dos últimos vestígios do império colonial. Essa crise teve um impacto imenso na sociedade espanhola pela humilhação que representou. Em outras palavras, a perda dos domínios fez com que a Espanha, nação que se sentia o centro do mundo, se voltasse para dentro de si mesma, questionando o seu destino.

Em 1890, Portugal igualmente passou por um episódio que foi tido como uma grande humilhação: o ultimatum inglês. A exigência, por parte da Inglaterra, de que Portugal retirasse os seus contingentes militares da África, não apenas acabou como o sonho português de construir a África Meridional Portuguesa como refletiu enormemente no imaginário do povo ao revelar a incapacidade do regime e a fragilidade política do país. O ultimatum deixou uma marca tão profunda que, em 1917, Álvaro de Campos, heterônimo de Fernando Pessoa, ao escrever o seu Ultimatum, de certa maneira, revisita o memorandum inglês. Nesse sentido, percebe-se que Fernando Pessoa, do mesmo modo que Ortega y Gasset, viveu em um período de deprimida vida social e de ineficiente e conturbada política.

Se a obra do criador dos heterônimos é mundialmente conhecida e reconhecida, não menos se pode dizer da Filosofia de José Ortega y Gasset, pois este é um filósofo universal que teve a sua obra traduzida e estudada em todas as línguas cultas, sendo considerado um dos cinco maiores pensadores do século XX. Os pontos em comum entre os dois autores não se limitam à contemporaneidade de ambos (o filósofo nasceu em 1883 e o poeta, em 1888) e ao 
fato de pertencerem a um convulso mundo ibérico. Há nos escritos desses gênios uma, dentre muitas questões, que é no mínimo intrigante: a percepção da realidade.

\section{A filosofia de Ortega y Gasset}

O núcleo do pensamento ortegueano é a metafísica, ou seja, a idéia sobre o que é a realidade. De acordo com o filósofo espanhol a realidade compreende o indivíduo e a sua circunstância. A máxima de Ortega y Gasset é "eu sou eu e minha circunstância". Isso significa que o individuo só se percebe enquanto tal, quando consegue apreender a sua circunstância, que é tudo o que está ao seu redor e que, de certo modo, o constitui. Segundo Fujauski (2003, p. 40) "a circunstância forma a outra metade da minha pessoa e eu preciso integrá-la a mim para ser eu mesmo".

Com relação a Fernando Pessoa, o que podemos dizer (e isto já é um lócus comum nos estudos críticos sobre o poeta) é que existe entre este e o real uma impossibilidade de compenetração, conhecida como o culto da intransitividade, que está na raiz do processo heteronímico. Assim, o poeta por não conseguir salvar (apreender) a sua circunstância, não se salva, não consegue ser ele mesmo. O individuo só pode ser o outro depois de ter sido ele mesmo e para isso a apreensão de circunstância é um pré-requisito, ao qual Pessoa abdica ao colocar entre si e a realidade um véu.

\footnotetext{
Há entre mim e o real um véu

A própria concepção impenetrável

Não me concebo amando, combatendo,

Vivendo como os outros. [...]

(PESSOA, 1991, p. 87)
}

De acordo com Fujawski (1965, p.71), “a intransitividade pode explicar o fracasso na vida pessoal do poeta das relações interindividuais". Quem não se possui enquanto indivíduo, não consegue responder ao outro. Por isso, talvez, as amizades de Pessoa sejam sempre distantes e o amor, devido a sua incapacidade de abandonar-se, se converta na sua grande impossibilidade.

Mas voltemos a Ortega y Gasset. No seu artigo Facciones del Amor, o filósofo faz uma distinção entre amor e desejo. Para ele, desejo é a tendência a possuir algo de tal forma que o objeto venha a fazer parte de mim. O desejo tem caráter passivo e morre quando é satisfeito. O amor, ao contrário, é um eterno insatisfeito e tem um caráter ativo, ou seja, eu vou até o objeto e me integro na sua existência. De acordo com Ortega y Gasset (1983, p. 554) “en el acto amoroso, la persona sale fuera de sí: es tal vez el máximo ensayo que la 
naturaleza hace para que cada cual salga de sí mismo hacia otra cosa. No ella hacia mí, sino yo gravito hacia ella.”.

Isto significa que o indivíduo que ama abandona toda a tranqüilidade e segurança que há dentro de si e "emigra virtualmente" (para utilizar o termo de Ortega y Gasset) na direção do objeto para estar com o mesmo em estado de união. Não em união física, mas numa convivência simbólica, que independe da distância espacial.

Amar equivale a querer a perfeição do amado e buscar constantemente afirmar o objeto do amor. Funciona dessa maneira no amor à arte, no amor à pátria, no amor a um ser humano. Nós nos integramos à existência do objeto, não duvidamos em nenhum momento do direito que o mesmo tem de existir e a sua causa passa a ser a nossa causa. Para o filósofo (1983, p. 559) "amar es vivificación perenne, creación y conservación intencional de lo amado".

Assim, Ortega y Gasset entende o amor como uma atividade sentimental até um objeto, que pode ser pessoa ou coisa. É um "caminhar da alma" na direção do amado. Logo, o amor é um ato transitivo em que a nossa atenção se fixa num objeto de tal maneira que não podemos sequer imaginar viver sem ele.

No que diz respeito ao amor sexual, o filósofo salienta a necessidade que o amante tem de dissolver a sua individualidade na individualidade do amado e, ao mesmo tempo, de absorver a individualidade do amado na sua. Foi exatamente isso que Fernando Pessoa não conseguiu fazer ou (talvez) do que abdicou em favor da sua obra.

\section{A impossibilidade do amor em Fernando Pessoa}

Na obra de Pessoa, o poeta múltiplo e que a tudo quer atingir, o amor surge como a grande impossibilidade. Essa constatação parece óbvia. Entretanto, é preciso procurar explicitar quais seriam as motivações dessa impossibilidade.

Os estudos de Ortega y Gasset sobre o amor consideram a importância desse assunto na vida dos homens. $\mathrm{O}$ aspecto mais significativo destes estudos é o reconhecimento de que as relações amorosas revelam o que somos verdadeiramente, desnuda nosso modo interior de ser.

Desde os gregos o amor e o ódio foram tomados como formas do desejo, do apetite sensível. Desse modo também se referiu a ele Santo Tomás, que reconhece a inclinação da natureza para algo, que é o amor, embora o distinga de um impulso puro e mais perfeito, chamado intelectual, "próprio dos anjos" (cf. CARVALHO, 2003, p.256). Esse amor mais 
perfeito, talvez sublimado, aparece na obra pessoana e nos dá um indício da sua impossibilidade amorosa. A racionalidade e o intelecto também são impulsos mais valorizados pelo poeta.

Mas eu, ao conceber-me amando, sinto

Como que um gargalhar hórrido e fundo

Da existência em mim, como ridículo

E desusado no que é natural.

(PESSOA, 1991, p. 96)

O impulso natural para ele é o intelectual. O amor é o ridículo desse estado natural.

As características observadas no amor são, pois, segundo o filósofo espanhol: ser contínuo, o ir ao objeto e aproximar-se dele, afastando-se de si. Sob o influxo do amor nos tornamos menos exigentes, claros e racionais do que somos em outras situações ordinárias da vida. Essas características de abandono do intelecto em detrimento do outro é impossível a Pessoa:

\footnotetext{
O amor causa-me horror; é abandono, Intimidade...

... Não sei ser inconsciente

E tenho para tudo [...]

A consciência, o pensamento aberto

Tornando-o impossível.

E eu tenho do alto orgulho a timidez

E sinto horror a abrir o ser a alguém,

A confiar n'alguém. Horror eu sinto

A que perscrute alguém, ou levemente

Ou não, quaisquer recantos do meu ser

(PESSOA, 1991, p. 89)
}

Segundo as conclusões de Ortega y Gasset, como referido anteriormente, o amor permanece insatisfeito porque nele aquele que ama não traz o outro para si, antes sai de si e vai até o objeto amado. Não pode tomá-lo para si, possuí-lo, submetê-lo ou não será amor. Aqui chegamos num intrincado nó. Fernando Pessoa, ao que concordam seus estudiosos "foi tanto o outro que não consegui ser ele mesmo". Ora, se ele foi tanto o outro como não conseguiu sair de si para amar? Voltemos à teoria ortegueana. Justamente por não conseguir ser ele mesmo é que não conseguiu chegar ao outro para amar. Para chegar ao outro é preciso estar inteiro. Se não conseguiu ser ele mesmo, nunca esteve inteiro. Por isso Pessoa, apesar de ter sido tanto o outro, jamais conseguiu sair de si, requisito indispensável para amar. Ortega y Gasset observa que o amor é um esforço de aproximação, às vezes não físico, com o amado. Quem ama deixa a tranqüilidade de estar em si e vai até o outro, mas vai inteiro. E direciona não de um golpe único, mas lenta e continuamente, como fruição constante. Esse ir até o outro, até o objeto amado, lenta e continuamente, sem submetê-lo é impossível para Pessoa.

Sinto preciso

Ocultar o meu íntimo aos olhares 
E aos perscrutamentos que olhares mostram; Não quero que ninguém saiba o que sinto, Além de que o não posso a alguém dizer...

... (PESSOA, 1991, p. 85)

Não me concebo amando, nem dizendo A alguém "eu te amo" — sem que me conceba Com uma outra alma que não é a minha Toda a expansão e transfusão de vida Me horroriza, como avaro a idéia De gastar e gastar inutilmente Inda que no gastar se [extraia] gozo. (PESSOA, 1991, p. 93)

O estado místico, bem como o enamoramento é uma forma de se transportar para fora de si e do mundo. Ambos nascem do empobrecimento da atenção, da sua concentração em uma única coisa. Apaixonar-se é se colocar sob uma forma específica de controle não racional. Ortega considera que "dizer que o homem é racional e livre [...] parece uma expressão muito próxima de ser falsa". Pessoa diz "não sei ser inconsciente". Contudo não se dá conta de que a liberdade e a racionalidade estão presentes na vida, mas só como uma película estreita, como já revelou a psicanálise.

O amor desencadeia um percurso psíquico dissolvente do qual é sempre difícil, senão impossível recuperar-se. E a isso Pessoa recusa.

Em alguns textos, o eu lírico lamenta um amor que poderia ter sido, mas não foi. É o que ocorre no poema “Aqui está-se sossegado". A ausência do amor traz a tranqüilidade, o sossego - que é o oposto da condição do enamoramento, quando o indivíduo abandona toda a calma, a segurança de estar em si para ir até o outro -, mas também causa a dor.

\footnotetext{
Aqui está-se sossegado ,

Longe do mundo e da vida, [...]

Os seus gestos inocentes

Tocavam no coração [...]

Nada explica nem consola.

Tudo está certo depois.

Mas a dor que nos desola,

A mágoa de um não ser dois

Nada explica nem consola.

(PESSOA, 1970, p. 113)
}

Por outro lado, no poema que segue, o amor, assim como as demais obrigações do cotidiano, é visto como uma prisão. O poeta precisa de liberdade para criar e por amor à arte deve abrir mão de qualquer compromisso que seja alheio ao fazer poético.

\footnotetext{
Quero ser livre, insincero

Sem crença, dever ou posto.

Prisões, nem de amor as quero.

[...]

(PESSOA, 1970, p. 172)
} 
A carta de rompimento do namoro com Ophélia Queirós, único relacionamento amoroso de Fernando Pessoa do qual se tem notícia, fala a mesma linguagem do fragmento acima, deixando claro que, para o poeta, a poesia estava em primeiro lugar. "O meu destino pertence a uma Lei de cuja existência a Ophelinha nem sabe, e está subordinado cada vez mais à obediência a Mestres que não permitem nem perdoam” (BERTOLOTTO, 2006, p. 34).

\section{Conclusões}

Por todas as considerações feitas até aqui, chegam-se as seguintes conclusões: Fernando Pessoa foi incapaz de viver o amor sexual - aquele no qual o indivíduo sente necessidade de dissolver a sua individualidade na individualidade do outro e de absorver a individualidade do outro na sua. Este é o amor impossível em Pessoa. As explicações para esta impossibilidade, conforme mencionamos, estão na intransitividade do poeta, ou seja, na sua falta de compenetração com a realidade, na impossibilidade de ser inteiro e no fato de o mesmo priorizar a sua obra, o intelecto, considerando o amor uma prisão.

Contudo, não se pode afirmar que Fernando Pessoa não amou. Ele amou a poesia. Ortega y Gasset (1983, p. 559) nos fornece a seguinte definição de amor: "es un acto centrífugo del alma que va hacia el objeto en flujo constante y lo envuelve en cálida corroboración, uniéndonos a él y afirmando ejecutivamente su ser". Logo, o poeta "caminhava constantemente" na direção da poesia, estava com a mesma em estado de união e lutava para afirmá-la. Portanto, a criação literária era o grande amor da vida de Pessoa, sem o qual ele não poderia viver e do qual buscava a perfeição. Este amor, não menor do que qualquer outro, talvez explique as motivações do poeta e a grandiosidade da sua obra.

\section{Referências}

BERTOLOTTO, Rodrigo. O heterônimo meigo das ridículas cartas de amor. Entre Livros, São Paulo, Ano I, n. 10, p.34, fev. 2006.

CARVALHO, José Maurício. Jul. 2003. O Amor no Raciovitalismo de Ortega y Gasset. Disponível <http://www.ufsj.edu.br/Pagina/anais/Arquivos/mauricio.pdf\#search=\%220\%20Amor\% em: 20no\%20Raciovitalismo\%20de\%20Ortega\%20y\%20Gasset\%22>. Acesso em 20 jun. 2006.

FUJAWSKI, Gilberto de Mello. Fernando Pessoa, o Outro. São Paulo: Conselho Estadual de Cultura, [1965]. 
. Ortega y Gasset, a aventura da razão. São Paulo: Moderna, 2003.

ORTEGA Y GASSET, José. Obras Completas. V.5. Madrid: Alianza, 1983.

PESSOA, Fernando. Fausto tragédia subjectiva. Rio de Janeiro: Nova Fronteira, 1991. . Poesias Inéditas (1919-1930). Lisboa: Ática, 1970. 